This version is a preprint, available for public distribution. For the version of record, see:

Dunaetz, D. R. (2020). Great Commission

Research Journal, 12(1), 1-17.

\title{
CHURCH-BASED RESEARCH: CHALLENGES AND OPPORTUNITIES
}

David R. Dunaetz, Editor

\section{Abstract}

Because the church is the body of Christ, research focused on the Great Commission and Jesus' concern for evangelism and disciple-making needs to be church-based. The goal of such research is to better share God's love to a world who does not know bim by building up a collection of knowledge that will enable us to do so. This research may be both theological (focusing on what the Bible and other theologians have said) and scientific (focusing on collecting new data and interpreting it, especially in light of theology). Church-based scientific research may be either qualitative (exploring broad ideas and phenomena in a relatively subjective way) or quantitative (testing specific ideas by collecting data measuring the variables of interest as objectively as possible). The Great Commission Research Journal is an especially appropriate outlet for publishing such research.

\section{Church-Based Research: Challenges and Opportunities}

The Church Growth movement (McGavern \& Wagner, 1990; McIntosh, 2003; Rainer, 1998; Towns et al., 2004; Wagner, 1984; Warren, 1995), the Church Health movement (Schwarz, 1996), and the Missional Church movement (Guder, 1998; Tang \& Cotherman, 2019; Van Gelder \& Zscheile, 2011) have produced a multitude of ideas concerning the nature of effective evangelism (Stetzer, 2006). There 
are dozens, if not hundreds, of principles that are said to be relevant to sharing the gospel with those who do not know Christ. Undoubtedly many, if not most, are true at least under some conditions. But how do we know which ones are true, and under what conditions? That is the purpose of research concerning the Great Commission: To discover the factors that influence the effectiveness of our efforts to obey the commandments that Jesus has given to us. This research must be church-based research because the local church is the body of Christ (I Cor. 12:27), the community of those who have been redeemed by their faith in Christ and the means by which God works through his people to accomplish his purposes.

\section{What is Research?}

Research is essentially what needs to be done to increase our knowledge about something. In some contexts, this can be as simple as reading what others have discovered about a topic. However, to gain new knowledge concerning a topic, that is, knowledge that does not currently exist, original research must be carried out which is based on what is already known about a topic and which uses methods that are likely to lead us to additional discoveries. In this sense, research is what results from science, "a set of methods used to collect information about phenomena in a particular area of interest and [to] build a reliable base of knowledge about them" (Bordens \& Abbott, 2011, p. 2).

As Christians, we may feel a tension concerning research. Because we have God's Word and the Holy Spirit within us, we already have "all things that pertain to life and godliness" (2 Pet 1:3, ESV) and research may not seem necessary. Yet, when research is viewed as an effort to obtain new knowledge, the value of research becomes clearer, "The heart of him who has understanding seeks knowledge" (Prov 15:4, ESV), "An intelligent heart acquires knowledge" (Prov 18:15, ESV). Knowledge cannot replace the Bible or the work of the Holy Spirit in leading us to live a life pleasing to God, but the more knowledge we have of how people think, feel, and behave, the better we can respond in love to the needs of those around us (Phil 1:9). This means that church-based research, for the Christ follower, is not undertaken simply for the sake of gaining new knowledge; its overarching goal, rather, is to better love others by finding the most effective ways to respond to their needs, especially their fundamental 
spiritual needs, "For what does it profit a man to gain the whole world and forfeit his soul?” (Mark 8:36, ESV).

In this sense, church-based research or Great Commission (Mt. 28:19-20) research has as a subgoal to build up a collection of evidence, leading to knowledge, concerning conversion, disciple making, following Christ, baptism, teaching what Jesus instructed, and experiencing life together as Christ's body the church. Similarly, this research should provide explanations, rooted in evidence, of the phenomena we observe, such as numerical church growth (as well as stagnation or decline), spiritual growth of the individual, the Christian's use of skills and spiritual gifts in churches, and engagement in and commitment to the ministries of a church. To the degree we increase our knowledge concerning how and why these phenomena occur, we have successfully carried out Great Commission research.

Such research does not come naturally, even to Christian scholars who have been trained in the necessary methods. Such research requires both skepticism and intellectual humility (Swanson, 2005). Skepticism is needed because people, including (or perhaps especially) Christians, often make bold claims that may or may not be true. C. Peter Wagner, a founding member of the Great Commission Research Network, claimed, "The single most effective evangelistic methodology under heaven is planting new churches" (1990, p. 11). Is this true? Asking such a question requires a skepticism that might not be appreciated by those who have great respect and esteem for Wagner (among whom I count myself), or for those who live in a context where such a statement is considered a self-evident truth. Yet research may indicate that it is not always true, and that other forms of evangelism may be more effective in some contexts (cf. Bell \& Davis, 2004). Such knowledge would be extremely useful but can only come from research rooted in a healthy level of skepticism.

Along with skepticism, high-quality research requires intellectual humility, an understanding that one's knowledge may be fallible and a willingness to change one's beliefs when presented with new evidence (Davis et al., 2016; Whitcomb et al., 2017). Few scientists believe that science can "prove" something (Popper, 1959; Stanovich, 2013); rather, research provides evidence for a theory or model of a phenomenon that the researcher is trying to better understand. The 
data that we collect might be quite accurate, but our interpretation of the data may not be. For example, as humans, we often succumb to a confirmation bias (Nickerson, 1998), the tendency to interpret ambiguous information in a way that confirms our existing beliefs. To overcome this bias, we must humbly be aware of our own intellectual limitations, the limitations of our data, and our tendency to see what we want to see. Similarly, although we may believe Scripture to be inerrant or infallible, intellectual humility requires us to admit that our interpretation of Scripture may, at least occasionally, be errant or fallible.

\section{Theological vs Scientific Research}

Among Christians, there is a wide range of approaches to research. One way to classify them distinguishes between theological research and scientific research. Theological research, along with research in fields that emphasize history, applies systematic methods focusing on existing writings or documents along with logical reasoning to come to conclusions. These documents may include the Bible, historical documents produced by churches such as confessions and creeds, foundational writings by theologians (e.g., Calvin, Luther, and Wesley), or other theological treatises, essays, and research. Logical reasoning is then applied to come to conclusions relevant to the question or problem that is being addressed.

In theological research, generally no new data is collected nor are there empirical tests (e.g., repeatedly measuring a phenomenon in different conditions to understand how the conditions affect the phenomenon) to see if the conclusions are true. For example, in soteriology, the question of perseverance of the saints and/or synergism cannot be studied by putting people who self-identify as Christians into various situations and then observing which ones obtain eternal life. Rather, we discuss what the Bible says, what theologians have said, and the logical implications of the various concepts, perhaps seeking to integrate the material with contemporary concepts or to apply it to contemporary problems.

If God has truly revealed himself through Jesus Christ and the Scriptures, theological research lays the foundation for understanding not only our very existence, but also all that we can observe empirically. A theologically informed worldview enables us to understand the 
purpose of what we observe and enables us to view phenomena from an eternal perspective, rather than a simple temporal perspective. It enables us to understand observable phenomena from a macroscopic or "big picture" perspective, rather than a microscopic perspective that naturally results from a limited set of data.

Thus theological research depends heavily on the method of authority (Peirce, 1877) and rationalism (Descartes, 1637/2000). The method of authority, basing conclusions on what an accepted authority says on a topic, is only effective in discovering truth to the degree that the authority is correct. If the authority is the Bible and the Bible is the Word of God, then such an approach is quite justified, albeit potentially limited by our fallible interpretations mentioned previously. If the authorities are human theologians, the approach is likely to be less effective. Nevertheless, Calvin, Luther, or Wesley may be more reliable than@MiddleSchoolTheologian on Twitter. Another limitation of this method is that some fallible authorities are more vocal or available than others, contributing to the echo chamber effect (Colleoni et al., 2014) that is so visible on our Facebook feeds; we are likely to believe that the authorities which are the most accessible to us represent a consensus of all authorities we deem reliable, which may be far from the truth (Bordens \& Abbott, 2011).

Similarly, rationalism (using reason to come to the knowledge of truth) in theological research has both strengths and weaknesses. Rationalism as a research method enables us to take the message of the Bible and make it relevant to today's context. This is one of the fundamental responsibilities of church leadership and the basis of all persuasive sermons. Its proper use is what makes most Christian books convincing. However, what is considered a clear and convincing argument for one person, may not at all be persuasive to another. Often, there are reasons to accept an argument in one direction as well as other reasons to accept an argument that goes in another direction. The number of unresolved theological debates in internet forums is a witness to the limitations of the rational approach to theology.

In contrast to theological research, scientific research, even church-based scientific research, does not seek to answer the big picture "Why?" and "For what purpose?" questions relevant to our existence. Rather, science is based on observation, interpreted by 
reason (Einstein, 1934). This empiricism, collecting and interpreting data based on real experiences, enables us to produce evidence useful for answering questions that revelation and rational thought alone may not be able to answer. Examples of such questions include "In what ways do twenty-first century North American Christians grow in their commitment to God in large churches compared to how they grow in their commitment to God in small churches?" and "Is pastoral narcissism tolerated in some cultures more than others?" Answers to such questions require observation and analysis and may significantly contribute to understanding how to better fulfill the Great Commission in our particular contexts.

At the center of the scientific method lies the idea of testing ideas. Our personal experience, what others claim to have experienced, or what we read in the Bible or elsewhere, accompanied by rational analysis, may lead us to tentative conclusions that may or may not correspond to objective reality, which, from a theological point of view, may be defined as God's perspective on the matter. If revelation or reason do not provide sufficient evidence, as is often the case given our penchant for being influenced by our self-serving biases (Forsyth, 2008; Miller \& Ross, 1975), empirical data may provide additional evidence to evaluate such hypotheses. However, it should be noted that data can only provide support for hypotheses, not proof (Crano et al., 2015). Rival hypotheses or theories may also account for the data. However, consistent evidence producing support for our hypothesis makes the evidence stronger. On the other hand, a lack of support may indicate that our hypothesis or theory needs refining or that we collected the data in a way that did not capture the phenomena we wished to observe. With enough evidence, more complete theories will eventually eliminate rival theories because they better account for the evidence. For example, if evidence is consistently found that larger churches are more likely to attract narcissistic pastors than smaller churches (Dunaetz et al., 2018; Puls, 2020), pastoral search committees can adjust their strategies to find the most appropriate pastor to best serve God in their context.

\section{Church-Based Scientific Research}

For several decades, church researchers have sought to use scientific research to better understand how to fulfill the Great Commission. 
This desire to better understand the phenomena associated with disciple making lay at the heart of the Church Growth movement of the 1970s and 1980s and the origin of the Great Commission Research Journal (McQuilkin, 1974; Towns, 1986; Towns et al., 2004; Wagner, 1973). Scientific research focused on the Great Commission has also been adopted in other contexts such as the Evangelical Missiology Society (Rommen \& Corwin, 1996), the Church Health movement (Schwarz, 1996), and, more recently, the Missional Church movement (Breen \& Gustafson, 2019), contexts in which scholars have tried to avoid some of the extremes of the twentieth century Church Growth movement (Stetzer, 2012; Towns et al., 2004) but holding to the same general goal of effective evangelism and church development.

Several difficulties exist in conducting research focused on themes related to the Great Commission. Perhaps the most obvious is that the primary outcome variables with which we are concerned, for example, an individual's salvation, is only known to God, as described in the parable of the wheat and tares (Matt. 13:24-30). Humans can only look for outwards signs of salvation (James 2:24), whereas God looks at a person's heart (I Sam. 16:7). Nevertheless, there are many outward behaviors and internal attitudes in individuals which can be measured (e.g., the fruit of the Spirit and the works of the flesh, Gal. 5:19-23), and one's beliefs, such as the faith that is associated with salvation, can be at least approximately expressed by individuals (Rom. 10:8-10) and measured by researchers.

Other difficulties concern the fact that the discipleship to which Christ calls us is always within a community, the church which is in a very real sense the body of Christ (I Cor. 12:27). Most scientific research concerning Christians, such as those found in the Journal of Religion and Health, Psychology of Religion and Spirituality, and the Journal for the Scientific Study of Religion, focuses on phenomena which occur within individuals, such as outcomes concerning health and mental wellbeing, that is, clinical outcomes. Studies focusing on outcomes related to Christian communities or relationships between Christians are less common. Because discipleship takes place in the context of the body of Christ, that is, an organization comprised of individual Christians, church-based research shares some of the difficulties that are 
encountered in other forms of organizational research, namely, ethical limitations and accessibility issues (Spector, 2001).

Because research in organizations, including churches, always involves real people in situations that are part of their life, we can only rarely conduct research in laboratory contexts where interventions with no real-life consequences can be used to conduct an experiment. Most people, and especially Christ-followers, would consider it unethical to conduct an intervention in a church that could potentially have negative consequences, e.g., ask the pastor to give a series of fireand-brimstone sermons one month and then to give a series of prosperity gospel sermons the following month, measuring the effect of each series on church members' behavior as the series progress. For this reason, surveys (rather than interventions) are more commonly used in church-based research. Rarely are there negative consequences to asking questions about one's beliefs, behavior, or health, especially when the surveys are anonymous. Similarly, unobtrusive observation can be used to collect data. However, this is limited to observable public behavior, such as counting the attendance in a worship service or observing how many people remain talking to people around them after the worship service ends for more than 30 seconds.

Another limitation of church-based research concerns accessibility. The unit of analysis, that is, the entity that is being analyzed in a study, may be either the individual, the small group, the church, or the network of churches such as the denomination. Collecting data from a sufficient number of entities can be very difficult. Suppose we determine that we need to collect data from 300 units to be reasonably sure of detecting a phenomena that we are interested in and of finding evidence strong enough that we can reasonably reject the idea that the results were obtained by chance (a typical desired sample size calculated by using a power analysis; Cohen, 1988). Finding 300 individuals to complete a survey may be doable. Collecting data on 300 small groups would be more difficult, as would be data on 300 churches. Collecting data on 300 networks would be more difficult still. This means that many studies that we would like to conduct will remain undone because collecting the data is beyond the means of most researchers. Nevertheless, Christ calls us to sacrificially love our neighbors (Mark 12:31, John 15:13), so we must be willing to 
pay the cost of discovering how to better love them whenever it is feasible.

\section{The Church-Based Research Process}

Figure 1 presents a simple model describing the church-based research process. These five steps (defining research objectives, research design, data collection, data analysis, and conclusions and reporting) provide a broad overview of how research can be done in churches and other contexts to understand how to better fulfill the Great Commission.

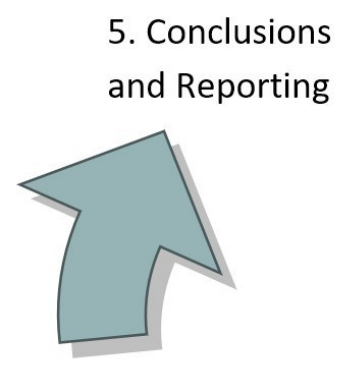

4. Data Analysis

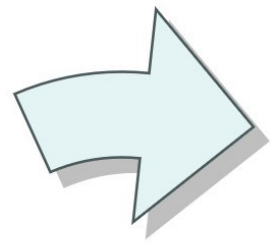

1. Defining Research Objectives

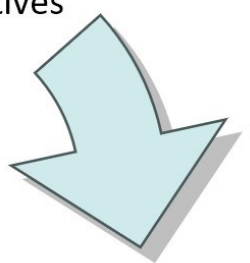

2. Research Design

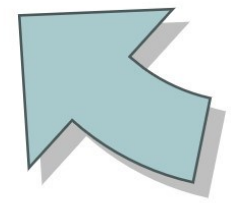

3. Data Collection

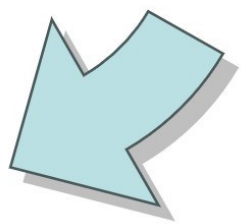

Figure 1. The Church-Based Research Process (Dunaetr, 2020)

\section{Defining Research Objectives}

The starting point for undertaking research is to clearly define one's research objectives. Does the researcher want to find out if an idea is 
true? Does the researcher want to better understand a phenomenon? Such questions may arise from the researcher's context, interests, or present needs. However, before defining the research objective, the researchers should become familiar with the previous research relevant to the topic (hence the arrow leading to the first step in the diagram). Researchers may start off by thinking they want to answer one question, but as they do a thorough review of previous research on the topic (commonly known as a literature review), they may realize that their question has already been answered, that there is a better or more important question to answer, or that the question needs to be reworked to maximize its usefulness or build upon previous research.

If the research is more general or exploratory in nature, a qualitative approach is often taken, that is, a rather subjective exploration of the subject to develop some ideas that might be true or generalizable to situations other than the exact situation studied (Creswell \& Poth, 2016; Patton, 2014). Qualitative research is subjective in that it is difficult to separate the values and biases that researchers bring to the research from the conclusions that they make. For example, if one researcher believes that exegetical preaching is the most effective way to influence non-Christians, then he is likely to collect data (e.g., interviews with people) and will interpret it in a way that supports his existing beliefs. If another researcher believes that topical preaching is the most effective way to influence non-Christians, he also might collect data, perhaps even by interviewing the same people, but he is likely to interpret what they say as indicating that his existing beliefs about preaching are true.

Despite its subjectivity, qualitative research is still quite valuable. The studies described above would undoubtedly provide insight into the positive effects of both expository and topic preaching, especially in the context studied (Salkind, 2017). They also might provide information that is useful to choose between the two approaches in a different context. Such research might also contribute to the formulation of a theory of when expository preaching is most effective and when topic preaching is most effective, a theory that could be tested with the second broad category of research, quantitative research. 
Quantitative research, in contrast to qualitative research, seeks to be as objective as possible, thus requiring an examination of much more narrow questions. Quantitative research seeks specifically to test the veracity of precise, limited statements, a process known as hypothesis testing (Fisher, 1925; Popper, 1959). Quantitative research is objective in that the researcher operationalizes the phenomena being studied by using clear definitions and procedures that can be used by other researchers. Thus quantitative research conducted by one researcher should lead to the same conclusion to which a different researcher would come, if they are using the same operationalizations and a sufficiently large and representative sample, and even if they start with different beliefs concerning the veracity of the hypothesis being tested or use different samples.

For example, in our preaching example, we may want to test the hypothesis that "Expository preaching has a greater influence on nonChristians than topical preaching" (or vice-versa). Both expository and topical preaching would need to be operationalized, perhaps with a questionnaire where auditors would indicate their agreement with a series of statements such as "The pastor spoke about a single passage in the Bible" (expository preaching) and "The pastor thoroughly addressed a topic that is relevant to today" (topical preaching). Such scales, typically consisting of a half-dozen to several dozen items, would need to undergo a series of validity and reliability tests to see if they are measuring what they are supposed to measure and if the measures are trustworthy. This is especially true because there is undoubtedly an overlap between expository and topical preaching and the two scales would be correlated to some degree. If the scales are trustworthy, they would be able to be used by other researchers to measure the degree to which an expository or topical message was heard by the auditor. Similarly, the influence that a sermon has on the non-Christian listening to it would need to be operationalized, perhaps by asking them a series of questions on how persuasive they found the sermon to be or to what degree they intend to change something in their life because of the sermon. Once the variables in questions are operationalized, a research design is chosen to test the hypothesis in a relatively objective way that should not depend on the presuppositions of the researcher. 


\section{Research Design}

Once the research question or hypothesis is well defined, the researcher needs to develop a plan for obtaining the relevant data. In theological research, this is often an extended literature review, perhaps seeking to apply texts, documents, or past research to the research question in a new way or a new context.

In qualitative research, the research question may be answered in a number of ways (Creswell \& Poth, 2016), perhaps via a case study or a biographical (narrative) study. More complex approaches include phenomenological research (describing how people have experienced a phenomenon), grounded theory (developing a theory based on people's experience), or an ethnography (a description and interpretation of a group's culture). Jay Moon's (2020) article in this issue is an example of grounded theory, a study resulting in a theory of choosing a form of alternative financing for a church, based on its assets and relational networks. The researcher must determine the most appropriate method of qualitative research based on their research questions, available resources, and their abilities. Data is typically collected through interviews, but may also include observations, focus groups, surveys, or artifacts, such as existing documents, artwork, or audiovisual materials.

In quantitative research, the principle research designs are either experimental or correlational. Experimental research designs, with random assignment of participants to one or more conditions, are preferred because they can demonstrate causation. If two groups are composed of individuals randomly assigned to different conditions (e.g., a service where the pastor preaches topical sermons and a service where the pastor preaches exegetical sermons), then any difference in group outcomes greater than what would be expected by chance is most likely due to the difference in conditions. However, such studies are difficult to carry out well in churches. Besides the ethical issues discussed previously, all confounding variables must also be controlled (e.g., time of service, relationships of people attending the service, the pastor's preference of styles, and a myriad of other potential confounds). 
For these reasons, most quantitative research designs in churches are not experiments but are correlational in nature, seeking to understand if two or more variables are related to each other or if there is a difference between specific groups of people. Such correlational studies can use easy-to-complete surveys with multiple-choice items, making them much more feasible. Nevertheless, great care must be used to operationalize the variables measured in order to have credible results. The correlations calculated can only describe how different phenomena move with each other; they cannot demonstrate that a change in one variable is caused by a change in another variable. Evidence for causation must be argued indirectly when an experimental design is not possible.

\section{Data Collection}

Once the researchers have prepared the interview protocol, the survey, or any other tool to be used to obtain the information needed, they may move toward data collection. Before data is collected, often the research protocol must be reviewed and approved by the Institutional Review Boards of the organizations with which the researchers are affiliated and by the appropriate authorities in the church or churches being studied.

Data for qualitative research most often comes from interviews. The researchers may have a fixed interview protocol used for all the participants, or the interviews may be less structured where the interviewer may adapt the questions according to the responses of the person being interviewed and to what has been learned in previous interviews. The researchers should continue to interview people until they reach saturation, the point where they sense that they are no longer getting new information relevant to the research question from additional interviews (Saunders et al., 2018).

Data for quantitative research in churches most often comes from surveys that measure all the variables in the hypotheses along with demographic information about the participants. The scales used to measure each of the variables should be psychometrically valid, so it is advisable to use preexisting scales for the variables in question, scales that have already proved their worth. Anonymity should be assured to maximize the likelihood of honest answers. The number of surveys 
needed (typically about 300) should be calculated with a power analysis before data collection begins. This prevents "fishing expeditions" and "p-hacking" where the researcher collects data until something interesting shows up, a process which makes the results less trustworthy (Head et al., 2015).

\section{Data Analysis}

After the data is collected, it must be analyzed. In qualitative research, this can be done manually, or with the help of software (Creswell \& Poth, 2016). The quality of the analysis, which is necessarily subjective, is heavily dependent on the skills of the researcher. The goal is to make sense of the data collected and to synthesize it in a way that provides at least partial answers to the research questions. The researchers must make a strong case that the data means what they claim it means.

In quantitative research, statistical analyses are performed on the data, in the manner determined at the time when the research was designed. Researchers often team up with statistical consultants for this analysis (and for the research design) as statistics are notoriously tricky and not easily mastered by the non-specialist. The goal is to determine if the data supports the hypothesis or not. If it appears highly unlikely that the results did not occur by chance (i.e., there is less than a $5 \%$ chance of getting these results if the hypothesis were not true), we say that the results are significant and that we have found evidence to support the hypothesis. If the results are not significant (i.e., there is more than a $5 \%$ chance of getting these results if the hypothesis were not true), we cannot make any conclusions; the hypothesis may be true, but it may not be. Finding support for the hypothesis is generally considered strong evidence since the research is designed to be as objective as possible, but there is always up to a $5 \%$ chance that the results were spurious, due to chance, not resulting from an actual phenomenon that could be expected to occur in other situations.

\section{Conclusions and Reporting}

After the data is analyzed, the researchers determine what they can conclude and create a report, providing details of how the study was conducted, the results, and an argument for their conclusions. For church-related studies, especially those related to evangelism and 
disciple making, submitting the resulting article to the Great Commission Research Journal is an excellent choice for disseminating the research to scholars and practitioners who have a heart for ministry. Before being accepted for publication, the article will be peer-reviewed, typically by at least two specialists. Based on the reviewers' comments, there will be a recommendation to either "reject," "revise and resubmit," "accept with conditions," or "accept unconditionally." If the recommendation is either of the middle two, the researcher is invited to rework the paper in light of the reviewers' comments and recommendations. The result is almost always a stronger paper.

The process for conducting research, including church-based research, is often slow and frustrating. Receiving a critical review of one's work can be painful and maddening, but after a week or so, the researchers often find that the reviewers' criticisms seem more reasonable. The goal of the Great Commission Research Journal is to publish high quality, trustworthy peer-reviewed research that is useful for others as they work to love and serve others through the proclamation of the gospel. As the editor of the Great Commission Research Journal, I encourage you to clarify the question you want to answer, design the research so as to find what you need to know, collect and analyze the data, and to write up the results so that a multitude of others may be able to benefit from your discoveries and the gospel may more effectively be proclaimed throughout the world.

\section{David R. Dunaetr, General Editor}

\section{References}

Bell, S., \& Davis, R. (2004). Church planting as growth strategy: Is it effective? Ministry, 76(4), 18-26.

Bordens, K. S., \& Abbott, B. B. (2011). Research design and methods: A process approach (8th ed.). Mc Graw-Hill.

Breen, M., \& Gustafson, D. (Eds.). (2019). Missional disciple-making: Disciple-making for the purpose of mission. $3 \mathrm{dm}$ International.

Cohen, J. (1988). Statistical power analysis for the behavioral sciences (2nd ed.). Lawrence Erlbaum Associates.

Colleoni, E., Rozza, A., \& Arvidsson, A. (2014). Echo chamber or public sphere? Predicting political orientation and measuring political homophily in Twitter using big data. Journal of Communication, 64(2), 317-332.

Crano, W. D., Brewer, M. B., \& Lac, A. (2015). Principles and methods of social research (3rd ed.). Routledge. 
Creswell, J. W., \& Poth, C. N. (2016). Qualitative inquiry and research design: Choosing among five approaches. Sage

Davis, D. E., Rice, K., McElroy, S., DeBlaere, C., Choe, E., Van Tongeren, D. R., \& Hook, J. N. (2016). Distinguishing intellectual humility and general humility. The Journal of Positive Psychology, 11(3), 215-224.

Descartes, R. (1637/2000). Discourse on method and related writings. Penguin.

Dunaetz, D. R. (2020). Research methods and survey applications (3rd ed.). Martel Press.

Dunaetz, D. R., Jung, H. L., \& Lambert, S. S. (2018). Do larger churches tolerate pastoral narcissism more than smaller churches? Great Commission Research Journal, 10(1), 69-89.

Einstein, A. (1934). On the method of theoretical physics. Philosopby of Science, 1(2), 163-169.

Fisher, R. A. (1925). Statistical methods for research workers. Oliver and Boyd.

Forsyth, D. R. (2008). Self-serving bias. In W. A. Darity (Ed.), International encyclopedia of the social sciences (2nd ed., Vol. 7). Macmillan Reference.

Guder, D. L. (Ed.). (1998). Missional church: A vision for the sending of the church in north America. William B. Eerdmans Publishing.

Head, M. L., Holman, L., Lanfear, R., Kahn, A. T., \& Jennions, M. D. (2015). The extent and consequences of p-hacking in science. PLoS Biology, 13(3), e1002106.

McGavern, D. A., \& Wagner, C. P. (1990). Understanding Church Growth (Third ed.). Eerdmans.

McIntosh, G. L. (2003). Biblical church growth: How you can work with God to build a faithful church. Baker Books.

McQuilkin, J. R. (1974). Measuring the Church Growth movement. Moody Press.

Miller, D. T., \& Ross, M. (1975). Self-serving biases in the attribution of causality: Fact or fiction. Psychological Bulletin, 82(2), 213-225.

Moon, W. J. (2020). Alternative financial models for churches and church plants: When tithes and offerings are not enough. Great Commission Research Journal, 12(1), 19-42.

Nickerson, R. S. (1998). Confirmation bias: A ubiquitous phenomenon in many guises. Review of General Psychology, 2(2), 175-220.

Patton, M. Q. (2014). Qualitative research \& evaluation methods: Integrating theory and practice (4th, Ed.). Sage Publications.

Peirce, C. S. (1877). The fixation of belief. Popular Science Monthly, 12, 1-15.

Popper, K. (1959). The logic of scientific discovery. Routledge.

Puls, D. (2020). Let us prey. Cascade Books.

Rainer, T. S. (1998). The book of Church Growth. B\&H Publishing Group.

Rommen, E., \& Corwin, G. (Eds.). (1996). Missiology and the social sciences:

Contributions, cautions, and conclusions. Evangelical Missiological Society Series. William Carey Library.

Salkind, N. J. (2017). Exploring research (9th ed.). Pearson.

Saunders, B., Sim, J., Kingstone, T., Baker, S., Waterfield, J., Bartlam, B.,

Burroughs, H., \& Jinks, C. (2018). Saturation in qualitative research:

Exploring its conceptualization and operationalization. Quality \& Quantity, 52(4), 1893-1907. 
Schwarz, C. A. (1996). Natural church development: A guide to eight essential qualities of bealthy churches. Churchsmart Resources.

Spector, P. E. (2001). Research methods in industrial and organizational psychology: Data collection and data analysis with special consideration to international issues. In N. Anderson, D. S. Ones, H. K. Sinangil, \& C. Viswesvaran (Eds.), Handbook of industrial, work and organizational psychology (Vol. 1, pp. 10-26). Sage.

Stanovich, K. E. (2013). How to think straight about psychology. Pearson.

Stetzer, E. (2006). The evolution of church growth, church health, and the missional church: An overview of the church growth movement from, and back to, its missional roots. Journal of the American Society for Church Growth, 17(1), 87-112.

Stetzer, E. (2012). What's the deal with the Church Growth movement? Part 2: Some unfortunate evolutions. The Exchange with Ed Stetzer. https://www.christianitytoday.com/edstetzer/2012/october/whats-dealw-church-growth-movement-part-2-some.html

Swanson, R. A. (2005). The challenge of research in organizations. In R. A. Swanson \& E. F. Holton (Eds.), Research in organizations: Foundations and methods of inquiry (pp. 11-26).

Tang, L., \& Cotherman, C. E. (Eds.). (2019). Sent to flourish: A guide to planting and multiplying churches. IVP Academic.

Towns, E. L. (1986). The relationship of church growth and systematic theology. Journal of the Evangelical Theological Society, 29(1), 63-70.

Towns, E. L., Van Gelder, C., Van Engen, C., Van Rheenen, G., \& Snyder, H. (2004). Evaluating the Church Growth movement: 5 views (P. E. Engle \& G. McIntosh, Eds.). Zondervan.

Van Gelder, C., \& Zscheile, D. J. (2011). The missional church in perspective: Mapping trends and shaping the conversation. Baker Academic.

Wagner, C. P. (1973). 'Church Growth': More than a man, a magazine, a school, a book. Christianity Today, 18(5), 11-14.

Wagner, C. P. (1984). Leading your church to growth. Regal Books.

Wagner, C. P. (1990). Church planting for a greater harvest: A comprehensive guide. Regal Books.

Warren, R. (1995). The purpose driven church : Growth without compromising your message \& mission. Zondervan.

Whitcomb, D., Battaly, H., Baehr, J., \& Howard-Snyder, D. (2017). Intellectual humility: Owning our limitations. Personality and Social Psychology Bulletin, 43(6), 793-813. 